\section{Epidemiology and Outcome of Exit Site Infection Catheter Related Among Patients from a Brazilian Haemodialysis Unit}

\section{Journal of \\ Urology \& Nephrology}

\section{Daniela Bueno Goulart, Marcela Lara Mendes, Leandro Vinícius de Souza, Edwa Bucuvic, Tricya Vieira Nunes Silva Bueloni and Daniela Ponce* Botucatu School of Medicine, UNESP, Sao Paulo, Brazil}

Address for Correspondence

Daniela Ponce, Distrito de Rubiao Junior, Botucatu School of Medicine, UNESP, Botucatu, Sao Paulo, Brazil, Tel: 5514 97625806; E-mail: dponce@fmb.unesp.br infection

\begin{abstract}
Patients undergoing haemodialysis (HD) are at high risk for healthcare-associated infections. There are scarce data on epidemiology of exitsite infection (ESI) related to tunneled centralvenous catheter (CVC) and the most studies focused only on bloodstream infections (BSI) and were performed in developed countries. Our study aimed to provide a wide overview of ESI epidemiology in a Brazilian $\mathrm{HD}$ unit. We presented data from prospective surveillance carried out from March 2010 through March 2015. The overall incidence of ESI was 3.50 per 1,000 catheters-days. Risk factors for ESI were presence of diabetes and tunneled CVC implanted in femoral site ( $R R=1.56,95 \%$ $\mathrm{Cl}=1.35-1.89$ and $\mathrm{RR}=1.62,95 \% \mathrm{Cl}=1.22-1.94, \mathrm{p}<0.05$, respectively). The most frequent agents of ESI were Gram-negative (69\%), mainly Serratia marcences, E coli, Proteus mirabillis, Pseudomonas aeruginosa and Klebsiela ESBL. Across the time periods, there was change in etiologic agents: Pseudomonas and ESBL agents became more frequent, while Proteus and E. coli became less frequent $(p<0.05)$. Among Grampositive agents, $59 \%$ were resistant to methicillin. On the other hand, Gram-negative bacilli were not often multidrug-resistant. Catheter was removed in $17 \%$ due to unsuccessful treatment of ESI and it was associated with Pseudomonas $(\mathrm{p}=0.04)$ and $\mathrm{BSI}$ caused by the same agent of ESI $(p=0.03)$. Catheter survival was shorter in ESI group (log rank=2.92, $p<0.001$ ). As conclusion, ESI rate was high on HD patients, and diabetes and femoral site of CVC were identified as risk factors for it. Catheter survival was shorter in patients who had ESI and catheter removal was associated with Pseudomonas agent and ESI plus BSI. Although Gram negative agents were more frequent, most of them were not resistant to quinolone, aminoglycoside and third generation cephalosporin. Our data suggest the routine application of topical antibiotic ointments to prevent ESI related to CVC caused by Gram negative agents.
\end{abstract}

\section{Background}

Patients undergoing haemodialysis (HD) are especially prone to acquiring healthcare-associated infections (HAI) [1]. This is due both to the dialysis procedure and to the immune suppressing effects of the underlying disease [2]. According to American data, infection is the second cause of death in patients on HD and vascular access is a major risk factor for bacteremia and hospitalization [3].

The type of vascular access most associated with infectious is central venous catheter (CVC), which also increases morbidity and mortality rates, as well as HD cost [3]. Catheter-related infections encompass exit site infections (ESI), tunnel infections, and bloodstream infectious (BSI) [4]. There is a substantial amount of literature on this subject; however, the most papers focused specifically on BSI [4-6].

Therefore, the National Kidney Foundation Kidney Disease Outcomes Quality Initiative (NKF KDOQI Clinical Practice

\begin{abstract}
Submission: 19 April, 2016
Accepted: 21 May, 2016

Published: 26 May, 2016

Copyright: ๑ 2016 Goulart DB,et al. This is an open access article distributed under the Creative Commons Attribution License, which permits unrestricted use, distribution, and reproduction in any medium, provided the original work is properly cited.

Reviewed \& Approved by: Dr. Yuling Chi, Department of Medicine, Division of Nephrology, Albert Einstein College of Medicine, Yeshiva University, USA
\end{abstract}

Guidelines) discourages the use of CVC and recommends that fewer than $10 \%$ of patients should use them [7]. However, because of tunnelled CVC introduction in 1980, the number of prevalent HD patients dialyzing through $\mathrm{CVC}$ has progressively increased.

Randomized controlled trials have demonstrated that tunnelled, cuffed catheters are associated with lower risk of bacterial colonization, ESI, and bacteraemia compared with non-tunnelled CVC [8-12]. The protective effect of tunnelling and cuffing is due to the prevention of bacterial migration along the sinus tract and immobilization [9].

Since the vast majority of studies were conducted in developed countries [4] and the epidemiology of ESI related to tunnelled CVC is scarce, data on the ESI among patients on HD in developing countries are needed. The aim of the present study was to contribute to knowledge on this issue, presenting data on epidemiology and outcome of ESI in patients undergoing HD using tunneled CVC in a dialysis unit from Brazil.

\section{Patients and Study Design}

\section{Patients}

All adult patients with chronic kidney disease (CKD) stage 5 who required HD using new inserted tunneled and cuffed CVC at the University Hospital from Botucatu School of Medicine were invited to participate. Informed consent was obtained from all patients prior to their inclusion in the study and the protocol was reviewed and approved by the Research Ethics Committee of Botucatu School of Medicine.

\section{Study design}

This study was conducted from March 2010 to March 2015. An interventional nephrologist inserted tunneled CVC (Tal Palindrome, Kendall, Tyco Healthcare Div Mansfield, MA, USA) into the right or left internal jugular or femoral vein under ultra-sound and 
Citation: Goulart DB, Mendes ML, de Souza LV, Bucuvic E, Bueloni TV, et al. Epidemiology and Outcome of Exit Site Infection Catheter Related Among Patients from a Brazilian Haemodialysis Unit. J Urol Nephrol. 2016;3(1): 5.

ISSN: $2380-0585$

Table 1: Characteristics of patients using tunneled central venous catheter according to presence or absent of exit site infection.

\begin{tabular}{|c|c|c|c|}
\hline Characteristics & exit site infection & no exit site infection & p \\
\hline & $\mathrm{n}=195$ & $n=190$ & \\
\hline Male gender $(m) \%$ & $116(59.5)$ & $108(56.8)$ & 0.67 \\
\hline Age (years) & $59(48-67)$ & $57.5(46-66)$ & 0.72 \\
\hline \multicolumn{4}{|l|}{ Etiology of CKD (\%) } \\
\hline Diabetes & $102(52.3)$ & $66(34.7)$ & $<0.001$ \\
\hline Hypertension & $53(27.2)$ & $74(38.9)$ & 0.06 \\
\hline Others & $40(20.5)$ & $50(26.4)$ & 0.22 \\
\hline Albumin levels (mg/l) & $3.4(3.1-3.9)$ & $3.8(3.4-4.0)$ & 0.04 \\
\hline Body mass index & $20.4(18.2-21.8)$ & $19.8(17.9-20.9)$ & 0.32 \\
\hline \multicolumn{4}{|l|}{ Catheter site (\%) } \\
\hline Femoral Vein & $118(60.5)$ & $78(41.1)$ & $<0.001$ \\
\hline Internal jugular vein & $76(39)$ & $110(57.9)$ & 0.009 \\
\hline Time on dialysis (days) & $193.5(47-810)$ & $98(36-361)$ & 0.008 \\
\hline Time using catheter (days) & $154(116-184)$ & $128(74-175)$ & 0.07 \\
\hline BSI & $91(44.6)$ & $19(15.3)$ & $<0.001$ \\
\hline Catheter survival & $167(119-204)$ & $220(96-281)$ & 0.002 \\
\hline
\end{tabular}

BSI: Blood Stream Infection

fluoroscopic guidance. Prophylactic pre-operative antibiotics were not prescribed. Inserted catheters were managed using infection prophylaxis protocols in accordance with Guidelines for the Prevention of Intravascular Catheter-Related Infections, 2011 [13]. Chest radiographs were obtained after insertion to confirm the position of the catheter tip in the superior vena cava. CVCs were dedicated only to HD and were not accessed for other purposes. Transparent dressings with controlled permeability were routinely used. The antibiotic lock used was cefazolin $(10 \mathrm{mg} / \mathrm{ml})$, gentamicin $(5 \mathrm{mg} / \mathrm{ml})$ and heparin $(5,000 \mathrm{IU} / \mathrm{ml})$ solution during the interdialytic period. The solution filled the lumen of the catheter according to the size of it $(1.6,1.9$, or $2.1 \mathrm{ml})$.

At the time of inclusion in the study, demographic and clinical data were recorded. The end point of the study was epidemiology of ESI. ESI was defined as purulent exit site discharge or two out of three of exit site erythema, tenderness and induration with a positive culture [14]. Secretion was collected for culture using swab technique. Treatment was oral ciprofloxacin. The protocol was interrupted when the catheter was removed due to fistula use, change of dialysis method, transplantation, transfer of dialysis center, treatment failure of infectious, mechanical complications related to catheter and patients death.

\section{Microbiology}

Exit site swabs were obtained using sterile, pre moistened calcium alginate swabs in all suspected cases of ESI (erythema, tenderness, induration, or discharge). The swabs were streaked onto plates containing blood agar, colistin-nalidixic acid agar, McConkey's media, and mannitol-salt agar. All cultures were incubated at 35.8 ${ }^{\circ} \mathrm{C}$ for $48 \mathrm{~h}$ and examined daily for growth. Patients with suspected bacteraemia (fever greater than $37.8{ }^{\circ} \mathrm{C}$, rigors, leukocytosis, or clinically unwell) were investigated with exit swabs and at least two sets of blood cultures $(20 \mathrm{ml})$.

\section{Statistical analysis}

Data are represented as means and standard deviations or as medians and ranges. The Student's $t$ test and Kruskal-Wallis test were used to compare parametric and nonparametric patients' characteristics, respectively. Chi-square test or Fisher was used to compare proportions. ESI rate was presented in events for 1,000 catheter-days. Cumulative infection-free catheter survivals were determined using the Kaplan-Meier method and compared using the log rank test. A multivariate Cox's proportional hazards model was also applied, which included age, sex, body mass index, diabetic status, site of CVC and time on dialysis as covariates. All data were analyzed using the statistical software package SPSS release. P values $<0.05$ were considered statistically significant.

\section{Results}

\section{Patient characteristics}

Total of 385 patients undergoing $\mathrm{HD}$ required insertion of tunnelled and cuffed CVC at the University Hospital from Botucatu 
Citation: Goulart DB, Mendes ML, de Souza LV, Bucuvic E, Bueloni TV, et al. Epidemiology and Outcome of Exit Site Infection Catheter Related Among Patients from a Brazilian Haemodialysis Unit. J Urol Nephrol. 2016;3(1): 5.

ISSN: $2380-0585$

Table 2: Logistic regression analysis for exit site infection.

\begin{tabular}{|l|c|c|c|}
\hline & OR & IC & P \\
\hline $\begin{array}{l}\text { Time on dialysis before } \\
\text { CVC implantation }\end{array}$ & 1.02 & $0.98-1.04$ & 0.07 \\
\hline Time of catheterization & 1.03 & $0.99-1.03$ & 0.06 \\
\hline Diabetes & 1.56 & $1.35-1.89$ & 0.015 \\
\hline Albumin levels & 1.08 & $0.99-1.43$ & 0.09 \\
\hline Femoral site & 1.62 & $1.22-1.94$ & 0.011 \\
\hline BSI & 1.67 & $1.34-1.92$ & 0.023 \\
\hline
\end{tabular}

CVC: Central Venous Catheter; BSI: Blood Stream Infection

Table 3: Prevalence of infections related to catheter in haemodialysis patients across the time periods.

\begin{tabular}{|l|c|c|c|c|}
\hline & $\begin{array}{c}2010 \text { to } \\
2015\end{array}$ & $\begin{array}{c}\text { March 2010 } \\
\text { to September } \\
2012\end{array}$ & $\begin{array}{c}\text { October 2012 } \\
\text { to March } \\
2015\end{array}$ & P \\
\hline ESI/1000 CVC- day & 3.5 & 2.3 & 4.1 & 0.03 \\
\hline BSI/1000 CVC- day & 0.98 & 1.21 & 0.71 & 0.04 \\
\hline $\begin{array}{l}\text { catheter survival in 1 } \\
\text { year }\end{array}$ & $75.6 \%$ & $73 \%$ & $78 \%$ & 086 \\
\hline
\end{tabular}

CVC: Central Venous Catheter

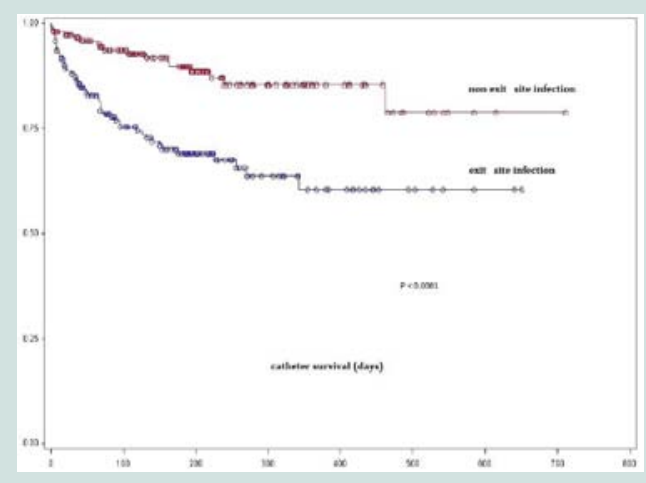

Figure 1: Catheter survival according to exit site infection.

School of Medicine between 1 March 2010 and 1 March 2015. All patients agreed to participate in the study and none lost to follow-up.

One hundred ninety patients (50.6\%) had ESI and 87 patients (22.6\%) had ESI and BSI caused by the same agent. The clinical and biochemical characteristics of patients who had and did not have ESI are shown in (Table 1). There were statistically significant differences between the two groups in presence of diabetes, albumin levels, site of catheter insertion, time on $\mathrm{HD}$ and time of catheterization.

Logistic regression model identified diabetic $(\mathrm{RR}=1.56,95 \%$ $\mathrm{CI}=1.35-1.89, \mathrm{p}<0.05)$ and femoral site $(\mathrm{RR}=1.62,95 \% \mathrm{CI}=1.22-1.94$, $\mathrm{p}<0.05$ ) as factor risk for ESI (Table 2).

During the study period, 153,131 patient-days were counted. This value was equal to the sum of CVC-days. There were 530 ESI and 151 BSI episodes. The pooled ESI incidence for the study period was 3.50 per 1,000 CVC days and BSI was 0.98. There was an increase in ESI and a decrease in BSI across the time (Table 3 ).

The most frequent agents of ESI were Gram-negative (69\%), mainly Serratia marcences, E coli, Proteus mirabillis, Pseudomonas aeruginosa and Klebsiela ESBL (Table 4). Across the time periods, there was change in etiology agents: Pseudomonas and ESBL agents became more frequent $(\mathrm{p}<0.05)$, while E.coli and Proteus became less frequent $(\mathrm{p}<0.05)$. Among Gram-positive agents, 59\% were resistant to methicillin. On the other hand, Gram-negative bacilli were not often multidrug-resistant. Resistance to quinolones, aminoglycosides, and third generation cephalosporins was found in less than $20 \%$ and $P$. aeruginosa and ESBL were resistant to carbapenems in less than $10 \%$.

Catheter was removed in $17 \%$ due to unsuccessful treatment and it was associated with Pseudomonas agent $(\mathrm{p}=0.04)$ and BSI caused by the same agent of ESI ( $\mathrm{p}=0.03$ ) (Table 5). Catheter survival was shorter in ESI group than in patients that did not have ESI (log rank=2.92, $\mathrm{p}<0.001$ ) (Figure 1).

\section{Discussion}

Vascular access is the 'Achilles heel' of HD [15-17]. Throughout the world, nephrologists are increasingly relying on indwelling dialysis catheters for long-term dialysis vascular access. In part, this trend is due to advanced patient age, the number of comorbidities, including diabetes mellitus and vascular disease, and the late age referral of patients with chronic kidney disease [15-20]. According to the US Renal Data System (USRDS), since 1993, the use of CVC has increased from less than 10 to more than $30 \%$ of all dialysis patients $[18,19]$. In recent data from Brazil, the percentage of patients who received dialysis via venous catheters increased from 10 to $15 \%$ [21].

Catheter-related infections encompass ESI, tunnel infections, and BSI; however, BSI are the most clinically important because of their

Table 4: Distribution of catheter related exite site infection etiology agents across the time periods.c

\begin{tabular}{|c|c|c|c|c|}
\hline & $\begin{array}{c}2010 \text { to } \\
2015\end{array}$ & $\begin{array}{c}\text { March } 2010 \\
\text { to September } \\
2012\end{array}$ & \begin{tabular}{|c|} 
October \\
2012 to \\
March 2015
\end{tabular} & $\mathbf{P}$ \\
\hline & $N=530$ & $N=165$ & $N=365$ & \\
\hline Gram positive & $164(31)$ & $60(36.4)$ & $104(28.5)$ & 0.001 \\
\hline Gram negative & $366(69)$ & $105(63.6)$ & $261(71.6)$ & 0.08 \\
\hline $\begin{array}{l}\text { Gram positive } \\
\text { resistant to } \\
\text { methicillin }\end{array}$ & $\begin{array}{c}97 \\
(59.1)\end{array}$ & $35(58.3)$ & $62(59.6)$ & 0.98 \\
\hline \multicolumn{5}{|l|}{ Gram negative } \\
\hline Serratia & $\begin{array}{c}108 \\
(29.5)\end{array}$ & 33 (31.4) & 75 (28.7) & 0.71 \\
\hline E coli & $\begin{array}{c}58 \\
(15.8)\end{array}$ & $28(26.7)$ & $30(11.5)$ & $<0.001$ \\
\hline Proteus & $\begin{array}{c}82 \\
(22.4)\end{array}$ & $35(33.3)$ & $47(18)$ & 0.002 \\
\hline Pseudomonas & $\begin{array}{c}71 \\
(19.4)\end{array}$ & $11(10.4)$ & $60(22.9)$ & 0.01 \\
\hline ESBL & $\begin{array}{c}58 \\
(15.8)\end{array}$ & $6(5.7)$ & $52(19.9)$ & 0.001 \\
\hline $\begin{array}{l}\text { Gram negative } \\
\text { resistant to } \\
\text { quinolone }\end{array}$ & $\begin{array}{c}73 \\
(19.9)\end{array}$ & $21(20)$ & $52(19.9)$ & 0.99 \\
\hline $\begin{array}{l}\text { Gram negative } \\
\text { resistant to } \\
\text { carbapenems }\end{array}$ & $35(9.6)$ & $9(8.6)$ & $26(9.9)$ & 0.83 \\
\hline
\end{tabular}


Citation: Goulart DB, Mendes ML, de Souza LV, Bucuvic E, Bueloni TV, et al. Epidemiology and Outcome of Exit Site Infection Catheter Related Among Patients from a Brazilian Haemodialysis Unit. J Urol Nephrol. 2016;3(1): 5.

ISSN: $2380-0585$

Table 5: Logistic regression analysis for catheter removal related to exit site infection.

\begin{tabular}{|l|c|c|c|}
\hline & OR & IC & P \\
\hline Age (per 1 year) & 0.988 & $0.973-1.004$ & 0.157 \\
\hline $\begin{array}{l}\text { Time on dialysis before } \\
\text { CVC implantation }\end{array}$ & 1.001 & $1.00-1.01$ & 0.07 \\
\hline Time of catheterization & 1.02 & $0.98-1.04$ & 0.08 \\
\hline Diabetes & 1.16 & $0.92-1.89$ & 0.09 \\
\hline Femoral site & 1.32 & $0.97-1.44$ & 0.12 \\
\hline ESI + BSI & 2.11 & $1.42-2.86$ & 0.03 \\
\hline Etiology agents & & & 0.04 \\
\hline pseudomonas & 1.68 & $1.35-1.99$ & 0.27 \\
\hline ESBL & 1.25 & $0.67-1.24$ & 0.58 \\
\hline G + resistant to methicillin & 1.15 & $0.79-1.49$ & \\
\hline
\end{tabular}

ESI: Exit Site Infection; BSI: Blood Stream Infection; ESBL: Extended Spectra Beta Lactamase

common occurrence and potential to transform into sepsis [22-32]. In our study, the general incidence of BSI was 0.98 episodes $/ 1000$ CVC-days and it decreased across the periods from 1.21 in 20102012 to 0.71 episodes/1000 CVC-days in 2012-2015. We believe it reduced due to prevention measures implemented, mainly the use of lock therapy solution. Welcome relief also has been observed in the USRDS 2009 data with a recent decline (2006-2007) in overall vascular access related hospitalizations due to infection, but they are still approximately two times higher than a decade before [7].

It occurred due to several prevention measures that have favorably affected BSI outcomes. These include the use of prophylactic topical antimicrobial ointments at the catheter exit site, the use of prophylactic catheter locking solutions for the prevention of CRB, strategies for management of the catheter in BSI, and the use of vascular access managers and quality initiative programs [31-35].

However, our study showed that the incidence of ESI increased across time periods from 2.3 to 4.1 episodes/1000 CVC-days. Unfortunately, no data on ESI related to CVC in patients undergoing $\mathrm{HD}$ are available in literature. We believe the rate of ESI increased across the time periods because no prevention measures for it were implanted. If they are implemented, we believe the ESI rate will reduce and probably, the BSI rate will decrease together.

It is somewhat surprising that epidemiological data on ESI related to CVC are so scarce because it is involved in the organisms extra luminal route and can lead to catheter-related bacteremia [36-38]. In this study, catheter survival was shorter in ESI group and its removal was associated with Pseudomonas agent $(\mathrm{p}=0.04)$ and BSI caused by the same agent of ESI $(\mathrm{p}=0.03)$.

The application of topical antibiotic ointments at the CVC exit site can be used to prevent ESI. They act as a barrier to limit the extra luminal route of organism and there are few reports on it. Some studies have shown that routine application of topical antibiotic at the CVC exit site was associated with a $75-93 \%$ reduction in the risk of BIS [31-33].

Mupirocin povidone-iodine, polysporin triple antibiotic ointment (gramicidin + bacitracin + polymyxin $\mathrm{B})$, and medical honey have been the most commonly studied substances [36]. In 2002, Johnson et al. conducted a randomized trial comparing the effect of exit site application of mupirocin vs. no ointment in $50 \mathrm{HD}$ patients with tunneled catheters [39]. Mupirocin reduced the incidence of ESI (6.6 episodes/1000 CVC-days vs. 0 in the mupirocin group; $\mathrm{p}<0.05)$ and BSI ( $35 \%$ vs. $7 \%$ in the mupirocin group; $\mathrm{p}<0.01$ ), and also increased median bacteremia-free survival from 55 to 108 days (log-rank score $7.0 ; \mathrm{p}<0.01)$. This improved infection-free survival was explained by a reduction in staphylococcal infection (log-rank=10.7; $\mathrm{p}=0.001$ ) [39].

A recent Cochrane systematic review demonstrated that mupirocin ointment reduced the risk of $\mathrm{BSI}(\mathrm{RR}=0.17$; 95\% $\mathrm{CI}=0.07$ 0.43 ) and had a significant effect on catheter-related infections caused by Staphylococcus aureus [40]. Nonetheless, only polysporin ointment showed a significant reduction in all-cause mortality $(R R=0.22 ; 95 \%$ $\mathrm{CI}=0.07-0.74)$, but had no effect on mortality related to infection [40].

According to our results, mupirocin must not be used in this Brazilian dialysis unit. The most frequent agents of ESI were Gramnegative $(69 \%)$ and among Gram-positive agents, 59\% were resistant to methicillin. On the other hand, Gram-negative bacilli were not often multidrug-resistant. Resistance to quinolones, aminoglycoside and third generation cephalosporins was found in less than $20 \%$. The use of topical ointments as aminoglycoside or medical honey to prevent BSI could be good options for preventing ESI and should be implanted soon.

We have to consider that the use of topical gentamicin can lead to emergence of strains resistant to gentamicin in the future. Medicalgrade honey can be another option. It has antimicrobial effects against resistant bacteria, protozoa, viruses, and fungi [41]. This is mediated by its high osmolarity, low water content, acidic $\mathrm{pH}$ (3.24.5 ), the generation of hydrogen peroxide upon its dilution, as well as its flavonoid and phenolic acid contents [41]. It has been shown to have equivalent efficacy as mupirocin for BSI prophylaxis [41]. Microbial resistance to honey has never been reported, also rendering it a promising future topical agent for CRB prophylaxis.

In conclusion, our study found that ESI rate has increased in our dialysis unit and that it is much more frequent than BSI. In addition, it allowed us to identify that Gram-negative bacilli are the main etiology agents and they are not often multidrug-resistant. However, most of Gram-positive agents are resistant to methicillin. ESI was an important cause of catheter removal when was associated with BSI and its agents are Pseudomonas. Above all, our data point out to the usefulness of applying topical prevent measures to aim the reduction the risk of CVC related infections and premature removal in patients with tunneled and cuffed HD catheters. Further studies are required to determine the optimal drug regimen for topical antimicrobial therapies, and its adverse effects.

\section{References}

1. Donlon S, Redmond A, McCann M, Einarsdottir H (2011) Prevention of infection in patients with chronic kidney disease part III: surveillance and auditing in a renal care environment. J Ren Care 37: 167-173.

2. Tokars JI, Miller ER, Stein G (2002) New national surveillance system for hemodialysis-associated infections: initial results. Am J Infect Control 30: 288-295.

3. Katneni R, Hedayati SS (2007) Central venous catheter-related bacteremia in chronic hemodialysis patients: epidemiology and evidence-based 
Citation: Goulart DB, Mendes ML, de Souza LV, Bucuvic E, Bueloni TV, et al. Epidemiology and Outcome of Exit Site Infection Catheter Related Among Patients from a Brazilian Haemodialysis Unit. J Urol Nephrol. 2016;3(1): 5.

management. Nat Clin Pract Nephrol 3: 256-266.

4. Bagdasarian N, Heung M, Malani PN (2012) Infectious complications of dialysis access devices. Infect Dis Clin North Am 26: 127-141.

5. Kybartienè S, Skarupskienè I, Ziginskienè E, Kuzminskis V (2010) Vascular access for hemodialysis: creation, functioning, and complications (data of the Hospital of Kaunas University of Medicine). Medicina (Kaunas) 46: 550-555.

6. Sucupira C, Abramczyk ML, de Abreu Carvalhaes JT, de Moraes-Pinto MI (2012) Surveillance system of hemodialysis-associated infections in a pediatric unit. Infect Control Hosp Epidemiol 33: 521-523.

7. Mermel LA, Allon M, Bouza E, Craven DE, Flynn P, et al. (2009) Clinical practice guidelines for the diagnosis and management of intravascular catheter-related infection: 2009 Update by the Infectious Diseases Society of America. Clin Infect Dis 49: 1-45.

8. Randolph AG, Cook DJ, Gonzales CA, Brun-Buisson C (1998) Tunneling short-term central venous catheters to prevent catheter-related infection: a meta-analysis of randomized, controlled trials. Crit Care Med 26: 1452-1457.

9. Flowers RH 3rd, Schwenzer KJ, Kopel RF, Fisch MJ, Tucker SI, et al. (1989) Efficacy of an attachable subcutaneous cuff for the prevention of intravascular catheter-related infection. A randomized, controlled trial. JAMA 261: 878-883.

10. Schwab SJ, Buller GL, McCann RL, Bollinger RR, Stickel DL (1988) Prospective evaluation of a Dacron cuffed hemodialysis catheter for prolonged use. Am J Kidney Dis 11: 166-169.

11. Timsit JF, Sebille V, Farkas JC, Misset B, Martin JB, et al. (1996) Effect of subcutaneous tunneling on internal jugular catheter-related sepsis in critically ill patients: a prospective randomized multicenter study. JAMA 276: 14161420.

12. Keohane PP, Jones BJ, Attrill H, Cribb A, Northover J, et al. (1983) Effect of catheter tunnelling and a nutrition nurse on catheter sepsis during parenteral nutrition. A controlled trial. Lancet 2: 1388-1390.

13. O'Grady NP, Alexander M, Burns LA, Dellinger EP, Garland J, et al. (2011) Summary of recommendations: Guidelines for the prevention of intravascular catheter-related infections. Clin Infect Dis 52: 1087-1099.

14. Jaber BL (2005) Bacterial infections in hemodialysis patients: Pathogenesis and prevention. Kidney Int 67: 2508-2519.

15. Moss AH, McLaughlin MM, Lempert KD, Holley JL (1988) Use of a silicone catheter with a Dacron cuff for dialysis short-term vascular access. Am J Kidney Dis 12: 492-498.

16. Schwab SJ, Buller GL, McCann RL, Bollinger RR, Stickel DL (1988) Prospective evaluation of a Dacron cuffed hemodialysis catheter for prolonged use. Am J Kidney Dis 11: 166-169.

17. Shusterman NH, Kloss K, Mullen JL (1989) Successful use of double-lumen, silicone rubber catheters for permanent hemodialysis access. Kidney Int 35 887-890.

18. CORR (2010) Treatment of end-stage organ failure in Canada 1999 to 2008 2010 Annual Report, Canadian Institute for Health Information, USA.

19. US Renal Data System (2009) Annual Data Report: Atlas of chronic kidney disease and end-stage renal disease in the United States. National Institutes of Health, National Institute of Diabetes and Digestive and Kidney Diseases, Bethesda, MD, USA

20. (2015) Censo Brasileiro de diálise 2014

21. Lugon JR (2009) Doença renal crônica no Brasil: um problema de saúde pública. J Bras Nefrol 31: 2-5.

22. Ishani A, Collins AJ, Herzog CA, Foley RN (2005) Septicemia, access and cardiovascular disease in dialysis patients: the USRDS Wave 2 study. Kidney Int 68: 311-318.
23. Engemann JJ, Friedman JY, Reed SD, Griffiths RI, Szczech LA, et al. (2005) Clinical outcomes and costs due to Staphylococcus aureus bacteremia among patients receiving long-term hemodialysis. Infect Control Hosp Epidemiol 26: 534-539.

24. Marr KA, Kong L, Fowler VG, Gopal A, Sexton DJ, et al. (1998) Incidence and outcome of Staphylococcus aureus bacteremia in hemodialysis patients. Kidney Int 54: 1684-1689.

25. Maraj S, Jacobs LE, Kung SC, Raja R, Krishnasamy P, et al. (2002) Epidemiology and outcome of infective endocarditis in hemodialysis patients. Am J Med Sci 324: 254-260.

26. Ramanathan V, Chiu EJ, Thomas JT, Khan A, Dolson GM, et al. (2007) Healthcare costs associated with hemodialysis catheter-related infections: a single-center experience. Infect Control Hosp Epidemiol 28: 606-609.

27. Mokrzycki MH, Zhang M, Cohen H, Golestaneh L, Laut JM, et al. (2006) Tunnelled haemodialysis catheter bacteraemia: risk factors for bacteraemia recurrence, infectious complications and mortality. Nephrol Dial Transplant 21: $1024-1031$

28. Tanriover B, Carlton D, Saddekni S, Hamrick K, Oser R, et al. (2000) Bacteremia associated with tunneled dialysis catheters: comparison of two treatment strategies. Kidney Int 57: 2151-2155

29. Silva TN, Mendes ML, Abrao JM, Caramori JT, Ponce D (2013) Successful prevention of tunneled central catheter infection by antibiotic lock therapy using cefazolin and gentamicin. Int Urol Nephrol 45: 1405-1413.

30. CDC (2010) Dialysis event reporting 2010.

31. Levin A, Mason AJ, Jindal KK, Fong IW, Goldstein MB (1991) Prevention of hemodialysis subclavian vein catheter infections by topical povidone-iodine. Kidney Int 40: 934-938.

32. Sesso R, Barbosa D, Leme IL, Sader H, Canziani ME, et al. (1998) Staphylococcus aureus prophylaxis in hemodialysis patients using central venous catheter: effect of mupirocin ointment. J Am Soc Nephrol 9: 10851092

33. Johnson LB, Jose J, Yousif F, Pawlak J, Saravolatz LD, et al. (2009) Prevalence of colonization with community-associated methicillin-resistant Staphylococcus aureus among end-stage renal disease patients and healthcare workers. Infect Control Hosp Epidemiol 30: 4-8.

34. Silva TN, Marchi D, Mendes ML, Barretti P, Ponce D (2014) Approach to prophylactic measures for central venous catheter-related infections in hemodialysis: a critical review. Hemodial Int 18: 15-23.

35. (2006) NKF-K/DOQI Clinical practice guidelines for vascular access: update Am J Kidney Dis 48: S176-S247.

36. Lok CE, Mokrzycki MH (2011) Prevention and management of catheterrelated infection in hemodialysis patients. Kidney Int 79: 587-598.

37. O'Grady NP, Alexander M, Burns LA, Dellinger EP, Garland J, et al. (2011) Summary of recommendations: Guidelines for the prevention of intravascular catheter-related infections. Clin Infect Dis 52: 1087-1099.

38. Betjes MG (2011) Prevention of catheter-related bloodstream infection in patients on hemodialysis. Nat Rev Nephrol 7: 257-265.

39. Johnson DW, MacGinley R, Kay TD, Hawley CM, Campbell SB, et al. (2002) A randomized controlled trial of topical exit site mupirocin application in patients with tunnelled, cuffed haemodialysis catheters. Nephrol Dial Transplant 17: 1802-1807.

40. McCann M, Moore ZE (2010) Interventions for preventing infectious complications in haemodialysis patients with central venous catheters. Cochrane Database Syst Rev 20: CD006894.

41. Molan PC (1992) The antibacterial nature of honey: 1 . The nature of the antibacterial activity. Bee World 73: 5-28. 